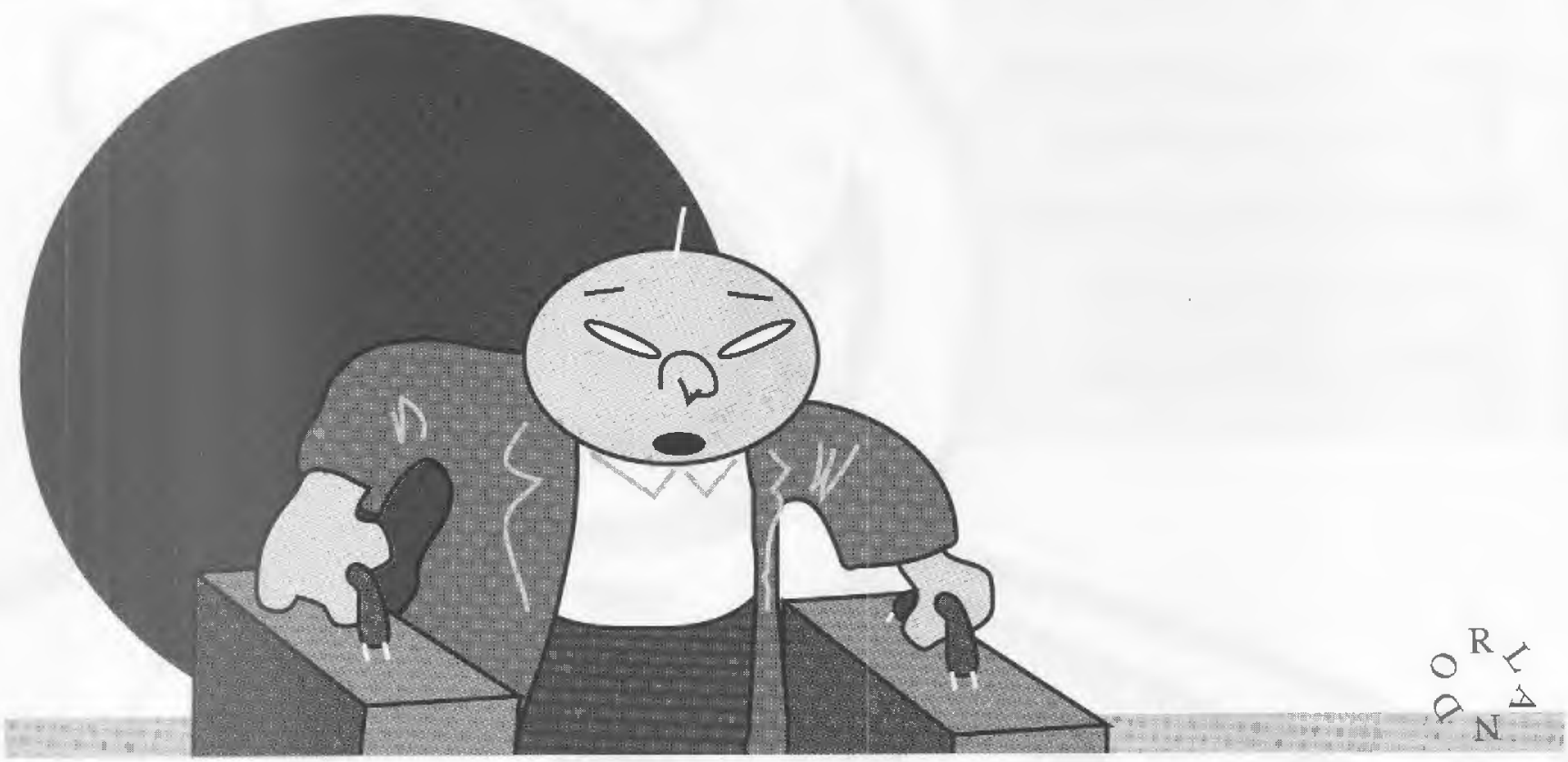

\section{MÃO-DE-OBRA DO BRASIL PARA O JAPÃO: ASPECTOS ECONÔMICOS E IMPACTOS NAS EMPRESAS DO FENÔMENO DEKASSEGUI *}

\section{Heitor Takashi Kato}

Doutorando em Administração Mercadológica na EAESPIFGV.

\section{- Silvio Yoshiro Mizuguchi Miyazaki}

Professor do Departamento de Economia da PUC/SP e Mestre em Economia e Finanças Públicas pela EAESP/ FGV.

\section{Alberto Issao Sugo}

Professor e Doutorando do Departamento de Administração Geral e Recursos Humanos da EAESP/ FGV.

* RESUMO: A crise econômica no Brasil e principalmente o desalento quanto às perspectivas de melhoras têm levado muitos brasileiros a procurar trabalhos desqualificados no exterior. UIm mozimento de transferência de trahalhadores brasileiros é aquele para o Japão, que vem ocorrendo desde 1985. Estes trabalhadores, japoneses e descendentes, seriam mais de 100.000. Neste artigo, procura-se verificar as causas e as consequiencias mais imediatas e perceptíveis deste processo, com ênfase nos impactos no mercado de trabalho e nas empresas.
* PALAVRAS-CHAVE: mäo-de-obra, mercado de trabalho empresas, Japão, migração, Brasil.

* ABSTRACT: Nowadays, Brazilian are looking for unskilled jobs in developed countries. These workers are pressured by theirs deteriorated economic conditions and perspectives. Japan has received since 1985 over 100,000 BrazilianJapanese and theirs relatives. The aim of this paper was to describe and to analyse the immediate implications of this workers migration, mainly in the labor market and in companies.

The findings of this article was supported by two surveys realized in May-June 1991, in Brazil.

* KEY WORDS: labor market, companies, Japan, migration, Brazil.

* Agradecemos a Toyota Foundation pelo financiamento da Pes quisa Trabalhadores Estrangeiros (nikkeis) no Japão da qual os autores participaram. Os dados primários que substanciaram este artigo foram coletados durante esta pesquisa. Agradecemos a Beneficência Nipo-Brasileira (enkyo), Câmara de Comércio e Ind ústria Japonesa no Brasil e as empresas e as pessoas que responderam os questionários. Colaboraram como assistentes de pesquisa: Elisa $M$. Sasaki, Erika Outa, Junko Nakahara e George H. Hirata e Gisela K. Ohnshi aos quais os autores são gratos. 


\section{INTRODUÇÃO}

As crescentes reduções salariais no Brasil, o desemprego e a falta de perspectivas paralelamente às melhores condiçōes de vida nos países industrializados fazem com que a emigração venha a crescer. Parte da populaçăo economicamente ativa do Brasil está se transferindo para esses países. Uma parcela da população brasileira, formada pelos japoneses e seus descencentes (nikkeis), está se dirigindo ao Japão para empregar-se. Esse fenômeno vem ocorrendo desde 1985.

O termo migraçāo designa qualquer deslocamento, suficientemente importante, de um grande número de pessoas. $O$ termo se aplica tanto ao movimento diário de trabalhadores dentro de uma grande aglomeração quanto à partida definitiva de um continente para outro.

O caso da saída de mão-de-obra brasileira para trabalhar no Japão (odekassegui) não parece se encaixar em nenhum dos extremos. É um caso de migração voluntária, não forçada.

Segundo Sauvy, para esclarecer as causas das migrações, é preciso distinguir dois pontos:

a) qual é a pessoa ou organismo, social ou político, que decide o movimento?

b) quais motivos levam esta pessoa ou organização à tal decisão?

No caso do dekassegui, não parece ter havido nenhum organismo, social ou político, que tenha iniciado o movimento. Entretanto, quando o volume de pessoas que afluíam ao Japão se tornou maior, empresas intermediárias e empresas receptoras de mão-de-obra começaram a participar do processo de migração dos descendentes de japoneses. Pode-se dizer que se configurou, então, o que Sauvy classificou como o estabelecimento de uma corrente regular: um início com saída individual se transformando e se desenvolvendo para uma saída organizada de indivíduos.

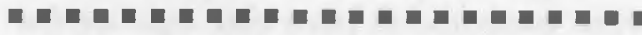 \\ Ser um dekassegui era mal visto dentro da comunidade japonesa no Brasil, tal como ocorria no Japão quando este termo foi cunhado. Desta \\ forma, os primeiros que seguiram \\ rumo ao Japão iam escondidos, não \\ comentando a viagem aos amigose nem mesmo aos parentes.}

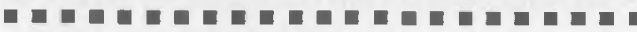

Quanto ao segundo aspecto, o que poderia ter motivado estes indivíduos a se arriscarem nesta empreitada? As razões básicas que deram curso a este movimento foram detectadas numa pesquisa que será analisada ao longo deste artigo.

Mas, além da análise do migrante, como as instituições encarariam a questão? Qual seria o ponto de vista daqueles que anteriormente contavam com esta força de trabalho? Como as empresas veriam cstc movimento que de maneira significativa drenou parcela da mão-de-obra brasileira de ascendência japonesa?

\section{HISTÓRICO}

A palavra dekassegui está sendo empregada para designar os trabalhadores brasileiros de origem japonesa e também japoneses radicados no Brasil, que estão

\section{Tabela 1}

\begin{tabular}{|c|c|c|c|c|c|c|c|}
\hline \multicolumn{8}{|c|}{ Entrada de brasileiros no Japão* } \\
\hline & 84 & 85 & 86 & 87 & 88 & 89 & $90^{* *}$ \\
\hline Entradas registradas & 9.250 & 13.889 & 13.434 & 12.126 & 16.789 & 29.241 & 57.423 \\
\hline Saidas registradas & 8.081 & 13.439 & 13.203 & 11.726 & 14.325 & 16.931 & 34.105 \\
\hline $\begin{array}{l}\text { Registro de permanência } \\
\text { temporária }\end{array}$ & 1.986 & 1.955 & 2.135 & 2.250 & 4.159 & 14.528 & 17.313 \\
\hline
\end{tabular}

Fonte: Ministério de Assuntos Estrangeiros do Japāo, 1991.

* Não registra o ingresso de pessoas com nacionalidade japonesa e clandestinos

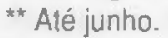

1. SAUVY, Alfred. Théorie Genérale delaPopulation. $3^{3}$ ed. Paris, Presses Universitaires de France, 1963, p. 249 .

2. A palavra japonesa dekassegui, utilizada para qualificar estas pessoas, signitica emigrante ou trabalho fora da residência. Era empregada no Japão para os trabalhadores do Norte e Nordeste, que iam à procura de trabalho nas regiōes desenvolvidas do Japão: Tóquio e Osaka. 
3.KATO, Heitor T.:MIYAZAKI, Silvio Y.M.:SUGO,Albertol. "Dekasseguimigraçāo de brasileiros ao Japāo". Japáo Informativo Econômico. Rio de Janeiro. Centro de Estucos Japoneses da Escola de Pós-Graduação em Economia (EPGE) da FGV. 3(9):2-3, Outubro de 1991.

4. Nos últimos anos (1986-1989) o número de estrangeiros que ingressaram no Japão com vistos ce turistas e que estavam se empregando ilegalmente estava aumentando rapidamente, causando um problema social e econômico. Em dezembro de 1987 o Ministério do Trabalho criou 0 Study Group Regarding the Foreign Worker Issue, que rum relatório de março de 1988, éz um plano de medidas para relorçar sua política para aceitação de estrangeiros com habilidades profissionais e técnicas e que näo substituíssem os japoneses. Entretanto, acrescentou-seno relatório que se deveria ser prucente na aceitação ce trabalhadores estrangeiros como mão-deobra desqualiticada, haja visto as experiências por que passaram outrasnaçōes desenvolvidas. JAPAN, Ministry of Labor. Employment Security Bureau. Foreign Workers' Affaires. "Response to foreign worker issue". Japan Labor Bulletin. 28(11):5-7, nov. 1989

5. Em pesquisa sobre a populaçāo nikkei residente no Brasil, reaizada entre 1987 e 1988, fol estimado um total de 1.168 .000 pessoas (limites de erro de mais ou menos 22.000) descendentes de japoneses no pais. CENTRO DE ESTUDOS NIPOBRASILEIROS. Pesquisa da População de Descendentes de JaponesesResidentes no Brasill. São Paulo, junho de $1988,0.9$.

6. Burajirukarano Nikkei Dekasegui Rodoshano littaito Nihonshakaideno Tajyou - Burajirugawa Hokokusho. [A situação dos trabalhadores nikkeis emigrados do Brasil e a sua relação comasociedade japonesa - Relatório Brasileiro]. SãoPaulo. s.c.e. mimeo. 1991. indo ao Japão realizar tarefas desqualificadas. Estes dekasseguis brasileiros começaram a chegar ao Japão a partir de 1985, com um grande aumento do seu fluxo a partir de 1989.3

No começo, as condições para a emigração eram precárias: o trabalho no Japão era ilegal, as agências de viagens não estavam preparadas para este tipo de tramitação, não existiam agências de emprego intermediando os contatos entre empresas no Japão e possíveís candidatos no Brasil.

A partir de 1989, no Brasil, a saída de descendentes de japoneses se transformou em um fluxo significativo com mudanças no processo de emigração. Surgiram agências para a intermediação, cursos de língua japonesa passaram a atender pessoas interessadas em trabalhar no Japão, os vôos começaram a sair lotados e se formaram filas para a obtenção de vistos para o Japão.

Os primeiros que foram enfrentaram uma situação de trabalho ilegal. Com o tempo, em virtude da própria dimensão do fenômeno, o governo japonês criou brechas na legislação ${ }^{4}$, permitindo a aceitaçāo do imigrante como trabalhador, desde que descendente de japoneses( regulamentaçāo em vigor a partir de junho de 1990).

Ser um dekassegui era mal visto dentro da comunidade japonesa no Brasil, tal como ocorria no Japão quando este termo foi cunhado. Desta forma, os primeiros que seguiram rumo ao Japão iam escondidos, não comentando a viagem aos amigos e nem mesmo aos parentes. Razões econômicas, situaçôes de extrema dificuldade, eram os motores dessa saída do Brasil.

Com o crescimento do fluxo e o relato de sucessos em ganhos em curto período de tempo, ser dekassegui perdeu sua conotação pejorativa dentro da colônia, ocorrendo mesmo uma certa inversão de valores, com os indivíduos remanescentes tendo que "se explicar" por nāo terem ido ainda para o Japão. Esta pressão tornou-se mais um fator impulsionador do fluxo ao Japão.

Portanto, se a pressão social anterior fazia com que apenas algumas pessoas de cada família viajassem para o Japão com o propósito de exercer um trabalho não qualificado, com a aceitação social, famílias inteiras têm viajado, agora já não mais em segredo.
Para se ter a dimensão do fenômeno, estima-se hoje em torno de 100.000 a 150.000 o número de dekasseguis (japoneses radicados no Brasil, brasileiros descendentes de japoneses e outros ligados por laços de parentesco). Esta população representa cerca de $10 \%$ do total da comunidade japonesa no Brasil. ${ }^{5}$

\section{PERFIL}

Os dados utilizados para análise do perfil do indivíduo dekassegui são primários e foram coletados principalmente na pesquisa realizada entre abril e julho de $1991 .^{6}$

Na pesquisa, tentou-se levantar dados sobre as características dos indivíduos referentes aos fatores que levaram a ida ao Japão, condições de trabalho e razões de retorno ou não ao trabalho no Japão. A metodologia de coleta de dados consistiu na aplicação de questionários semi-abertos e de entrevistas extensas para os indivíduos. Três tipos de questionários foram aplicados no Brasil: (I) para dekasseguis que não pretendem repetir a experiência, (II) para dekasseguis que pretendem retornar ao Japão e (III) indivíduos que pretendem tornar-se dekassegui. Além da pesquisa direta com dekassegui, levantaram-se dados secundários agregados do perfil dos dekasseguis.

Nesta análise, serão enfocados os que já passaram pela experiência de trabalho no Japão, ou seja, os que responderam os questionários de tipo (I) e (II). A amostra consistiu de 111 questionários, sendo 28 do tipo (I), 33 do tipo (II) e 50 do tipo (III).

\section{Tabela 2}

\section{Sexo dos dekasseguis}

\begin{tabular}{|lcc|}
\hline Sexo & $(1)$ & $(19 \ldots \ldots$. \\
\hline Masculino & 56,3 & 53,6 \\
\hline Feminino & 43,7 & 46.4 \\
\hline
\end{tabular}

Verifica-se pela tabela acima que não há uma diferenciação significativa na distribuição quanto aos sexos entre as categorias (I) e (II). Chama a atenção a proporçẫo relativamente alta de indivíduos do sexo feminino, quase equivalente ao masculino dentre os dekasseguis. Dentro da linha de produção de fábricas japonesas, em geral, 
destinam-se aos homens os trabalhos que exigem maior força física (em virtude, por exemplo, das condições ambientais mais adversas ou pela periculosidade). Para as mulheres, há muitas tarefas que exigem atenção, disciplina e perícia, tais como na conferência final de peças, montagem de componentes ou no manuseio e controle de ferramentas de alta precisão.

\section{Tabela 3}

Faixa Etária (\%)

\begin{tabular}{|lrc|}
\hline Idade & $(1)$ & $($ (1) \\
\hline De 10 até 20 & 0,0 & 0,0 \\
\hline De 20 até 30 & 66,7 & 56,1 \\
\hline De 30 até 40 & 6,7 & 10,5 \\
De 40 até 50 & 10,0 & 15,8 \\
\hline De 50 até 60 & 6,7 & 10,5 \\
Majs de 60 & 6,7 & 5,3 \\
\hline Não responderam & 3,2 & 1,8 \\
\hline
\end{tabular}

Quanto à distribuição etária dos dekasseguis, já se percebe uma pequena diferença entre as categorias (I) e (II). Os indivíduos que pretendem retornar ao Japão são um pouco mais idosos, com uma maior concentração nas classes acima de 30 e abaixo de 60 anos. Embora ambas as classes tenham a classe modal na categoria entre 20 e 30 anos, a concentração é mais expressiva para a classe dos que não pretendem retornar ao Japão(Ver tabela 3 ).

\section{Tabela 4}

\section{Grau de conhecimento da língua japonesa}

\begin{tabular}{|lcc|}
\hline & (I) & (II) \\
\hline Nenhum & 6,7 & 7,4 \\
Um pouco & 56,6 & 11,1 \\
\hline Bom & 36,7 & 81,5 \\
\hline
\end{tabular}

A tabela 4 é a primeira que exprime uma diferenciação nítida entre as categorias (I) e (II). A categoria dos que pretendem retornar ao Japão, em sua maioria $(81,5 \%)$, declararam saber japonês. De outro lado, apenas $36,7 \%$ dos que não pretendem voltar declararam o mesmo. Por estes dados, aparentemente o fator conhecimento da língua é fundamental para a adaptação e permanência do dekassegui.

\section{Tabela 5}

Tempo de estada no Japão como dekassegui

\begin{tabular}{|lcc|}
\hline & (I) & (ili) \\
\hline Menos que um ano & 84,8 & 28,6 \\
\hline a 2 & 6,1 & 67,8 \\
\hline a 3 & 9,1 & 3,6 \\
\hline
\end{tabular}

A tabela 5 também oferece uma boa visualização da diferenciação do perfil dos dois grupos. Enquanto os que não pretendem retornar, em sua maioria, não passaram de um ano no Japão, a classe (II) em sua maioria teve um período maior de estada no Japão. O período de menos de um ano parece ser suficiente para desestimular a permanência ou planos de retorno do dekassegui ao Japão. Este período de permanência tanto pode ter sido antecipadamente planejado quanto ter sido decidido durante o período de adaptação no Japão. De qualquer maneira, é bem provável que o conhecimento da língua (tabela 4) tenha sido determinante para esta configuração.

\section{Tabela 6}

\section{Causas que levaram a ir como} dekassegui ao Japão

\begin{tabular}{lccc|}
\hline & (1) & (It) \\
\hline Poupar & 19,2 & 49,3 \\
Comprar imóveís & 13,5 & 21,3 \\
Conhecer a cultura & & \\
e a língua japonesas & 21,2 & 28,4 \\
Voltar ao pais natal & 41,2 & - \\
\hline Visitar país dos ancestrais & 3,9 & - \\
\hline
\end{tabular}

A tabela 6 apresenta uma boa visualização das diferentes motivaçōes entre as categorias (I) e (II). De certa forma, responde a dúvida anterior sobre o período de permanência no Japão. A parentemente, os indivíduos da categoria (II) vão mais resolutos a permanecerem no Japão em virtude mesmo da própria base marcadamente econômica de sua motivação. Enquanto isto, os da categoria (I), aqueles que não pretendem retornar ao Japão, declararam motivos de ordem social e cultural. Interessante constatação é verificar que além da motivação econômica, razões de ordem 
cultural também motivaram os indivíduos a tentar a experiência de trabalho no Japão.

\section{Tabela 7}

Faixas salariais - ganhos no Brasil antes de ir ao Japão

\begin{tabular}{lcc|}
\hline Salários mínimos & (I) & (II) \\
Menos que um & & \\
salário mínimo & 5,0 & 0 \\
1 a 5 & 40,0 & 60,0 \\
5 a 10 & 30,0 & 35,0 \\
10 a 20 & 10,0 & 5,0 \\
Mais de 20 & 15,0 & 0 \\
\hline
\end{tabular}

Percebe-se aqui (tabela 7) uma forte razão para os que pretendem retornar ao Japão: o perfil de ganho desta classe no Brasil é claramente pior do que o da categoria (I). Embora haja alguns indivíduos que ganhem menos do que um salário mínimo na classe dos que não pretendem retornar, eles não são muito significativos.

Há uma proporção maior de indivíduos com faixas etárias superiores na categoria (II) do que na (I). Este perfil de idade mais avançada da categoria (II) leva a uma especulação de que tenham um número maior de compromissos assumidos assim como responsabilidades (por excmplo, família e fillhos), e por isso sintam mais forte a oportunidade de retornar ao Japão na sua tentativa de obter ganhos maiores.

\begin{tabular}{|c|c|c|}
\hline \multicolumn{3}{|c|}{$\begin{array}{l}\text { Média de horas-extras } \\
\text { realizadas do dekassegui }\end{array}$} \\
\hline & (1) & $(1 \mathrm{t})$ \\
\hline Nenhuma & - & 14,3 \\
\hline $0 \mathrm{a} 1$ & 4,0 & \\
\hline $1 \mathrm{a} 2$ & 52,0 & 39,2 \\
\hline $2 a 3$ & 8.0 & 32,2 \\
\hline Mais que 3 & 36,0 & 14,3 \\
\hline Total & 100,0 & 100,0 \\
\hline
\end{tabular}

Todas as tabelas sem citação da fonte dizem respeito a dados primários, coletados na pesquisa.

A classe que faz um número de horas extras maior (mais que 3 horas) é a dos que não pretendem retornar(I). Uma possível razão para isto é a de que estes, planejan- do já um regresso ao Brasil, procuram amealhar o máximo possivel no curto espaço de tempo de que dispõem. (Ver tabela 8)

A maior concentraçāo dos que pretendem voltar (II) nas classes de menores horas extras não surpreende. Pode espelhar uma proporção de emigrantes já adaptados à situaçăo no Japão e que não pretendam voltar ao Brasil tão cedo. Desta forma, ele procura não se sobrecarregar com uma jornada de trabalho muito extensa que dificilmente poderia manter por um longo período de tempo.

\section{Tabela 9}

Média de horas trabalhadas por dia do dekassegui

\begin{tabular}{|lcr|}
\hline & (I) & (II) \\
\hline 8 a 9 & 9,1 & 10,7 \\
\hline a 10 & 3,0 & 10,7 \\
10 a 11 & 39,4 & 35,7 \\
11 a 12 & 18,2 & 25,0 \\
Mais de 12 & 30,3 & 17,9 \\
Total & 100,0 & 100,0 \\
\hline
\end{tabular}

A tabela 9 mostra que mesmo aqueles que pretendem retornar ao Japão mantêm uma jornada extensa de trabalho. Deve-se ressaltar uma concentração expressiva $(30,3 \%)$ na jornada mais extensa na categoria (I).

Esta jornada de trabalho extensa se justifica pois apenas com o zanguiô (horas extras) se consegue economizar algum dinheiro. A tabela 14 apresenta o resultado de uma pesquisa a respeito de taxas de pagamento por horas adicionais de trabalho em empresas no Japão.

Há uma concentração maior dos indivíduos da categoria (I) na classe de ganhos superiores no Japão (mais que US\$2.000 mensais), condizentes com a distribuição de horas-extras e de poupança mostradas.

Como o custo de vida no Japão é alto, se comparado a outro países, a renda mensal de US\$1.000 pode ser considerada como a renda mínima para cobrir os custos com alimentação, vestuário, transporte interno, moradia etc. acrescida da eventual devolução do pagamento antecipado da passagem ida e volta entre o Brasil e o Japão. Isto também é coerente com os $16,1 \%$ da cate- 
goria (I) que recebem menos que aquele patamar mínimo de renda (Ver tabela 10).

\section{Tabela 10}

\section{Renda mensal no Japão do dekassegui} (US\$)

\begin{tabular}{|lcc|}
\hline & (1) & (II) \\
\hline Até 1.000 & 16,1 & 7,4 \\
1.00022 .000 & 35,5 & 59,3 \\
\hline Mais que 2.000 & 48,4 & 33,3 \\
\hline Total & 100,0 & 100,0 \\
\hline
\end{tabular}

Os $16,1 \%$ da categoria (I) também podem estar ligados aos dekasseguis que foram ao Japão motivados por fatores culturais e para tão somente visitar o país e à existência de algumas empresas cujas remunerações são menores ou em que há a impossibilidade de realização de horasextras principalmente pelos trabalhadores estrangeiros, resultando numa renda mensal menor que US\$1.000.

\section{Tabela 11}

Poupança mensal do dekassegui (US\$)

\begin{tabular}{|ccc|}
\hline & (1) & (1) \\
\hline 0 a 500 & 15,6 & - \\
500 a 1.000 & 9,4 & 25,9 \\
\hline 1.000 a 1.500 & 34,4 & 37,0 \\
Mais de 1.500 & 40,6 & 37,0 \\
Total & 100,0 & 100,0 \\
\hline
\end{tabular}

Como consequiência direta do número de horas-extras trabalhadas, aqui também se verifica uma concentração um pouco maior dos que não pretendem retornar na classe de maior poupança (mais de 1.500). A ausência de pessoas da categoria (II) na classe de baixa taxa de poupança nāo surpreende. Não obstante, a diferença no rendimento entre as classes nāo é tão grande assim. Isto poderia indicar que há duas estratégias de ganho diferentes entre as classes: a classe dos que não pretendem retornar seria a dos que não se adaptaram ao meio social e nāo conheceriam outro meio senão procurar trabalhar muito no emprego em que já estivessem; e a dos que pretendem retornar seria a de procurar otimizar ao máximo o ganho do trabalho, procurando ativamente por empregadores que pagassem mais. Outra hipótese que poderia ser colocada é que os indivíduos da categoria (I), como não pretendem retornar, consomem mais bens duráveis $\mathrm{e}$ de lazer. Desta forma, o volume poupado seria relativamente equivalente entre as duas categorias (Ver tabela 11).

\begin{tabular}{|c|c|c|}
\hline \multicolumn{3}{|c|}{$\begin{array}{c}\text { Mudança de emprego durante } \\
\text { o trabalho no Japão }\end{array}$} \\
\hline & (1) & (ii) \\
\hline Permaneceu no mesmo & 78,1 & 50,0 \\
\hline vez & 12,5 & 7,1 \\
\hline 2 vezes & 6,3 & 25,0 \\
\hline 3 vezes ou mails & 3.1 & 17.9 \\
\hline Total & 100,0 & 100,0 \\
\hline
\end{tabular}

A tabela 12 sugere que há nítidas diferenças de estratégia entre as categorias. Os que pretendem retornar ao Japão parecem mais interessados na procura de uma posição melhor dentro do mercado de trabaIho japonês. Ressalte-se que, ainda assim, a metade destes permaneceu no mesmo emprego durante o período de estada no Japão.

\section{Tabela 13}

\begin{tabular}{|lr|}
\hline Principal causa da mudança de emprego \\
\hline Trabalho árduo & $(11)$ \\
\hline Remuneração baixa & 42,3 \\
Discriminaçăo & 42,3 \\
Inoompreensão & 7,2 \\
Total & 7,2 \\
\hline
\end{tabular}

Analisando a tabela 13 referente apenas aos que pretendem retornar ao Japão, percebe-se uma pequena proporção de determinantes sociais para a mobilidade no emprego. São predominantes as causas relacionadas às próprias condições de trabalho. Esta maior iniciativa pode refletir a forte motivação econômica dos indivíduos da categoria (II).

Vale observar que no Japão há diferenças quanto ao pagamento de horas adicionais de trabalho': horas-extras, trabalho
7. 0 artigo 36 do Labor Standards Law (do Japâo) concede a permissão para 0 trabalho em períodos além da jornada normal, nāo havendo limites nem para as horas traba. Ihadas nem para o valor do pagamento de horas- extras. OMI, Naoto. "Labor sets its sights on the 1,800hour year". Economic Eye.Spring 1992. Tokyo. Keizai Koho Center, p. 11. 
8. "Um estudo da Câmara de Comércio e Indústria de Tóquio realizado em outubro de $1989,90 \%$ das empresas defrontam-se com este probiema. Ao lado do déficit há uma dificuldade de se recrutar trabalhadores năo qualificados (japoneses)..."; ISHIKAWA, Akihiro. "Formation et différenciation du marché des travailleurs étrangers au Japon". Sociologie du Travail XXXIII, ח? 1/1991. p. 176.

9. Com a escassez de mâo-de-obra recrutam-se trabahadores estrangeiros de países asiáticos em vias de desenvolvimento, uma força de trabaho atraída pelo mercado japonês apesar de o governo japonès ter uma severa política de controle de migração de trabahadores estrangeiros.ISHIKAWA, Akihiro. Op. cit. p. 173.

10. JOHNSTON, William8, "Otraba tho não tem pátria". Negócios em Exame, 10 de julho de 1991, p. A-2. noturno e trabalho em dias de folga. Comparando os dados da tabela 14 com o da média de horas trabalhadas por dia pelos dekasseguis, pode-se observar que é grande a proporção daqueles que trabalhavam mais que as oito horas de jornada normal, para justamente obter aqueles ganhos adicionais por horas-extras trabalhadas.

\section{Tabela 14}

Taxas de pagamento adicional por horas-extras (\% de empresas)

\begin{tabular}{|c|c|c|c|}
\hline Taxa & $\begin{array}{c}\text { Horas extras } \\
\text { normais }\end{array}$ & $\begin{array}{l}\text { Trabalho } \\
\text { potutno }\end{array}$ & $\begin{array}{l}\text { Trabalho em } \\
\text { dias de folga }\end{array}$ \\
\hline $25 \%$ & 40,8 & - & 27,4 \\
\hline $25 \%$ a $30 \%$ & 139 & 2 & 4,3 \\
\hline $30 \%$ & 41,8 & - & 29,3 \\
\hline $30 \%$ a $50 \%$ & 3,2 & $=2$ & 33,3 \\
\hline $50 \%$ & 0,3 & 25,9 & 4,9 \\
\hline $50 \%$ a $60 \%$ & & 15,4 & \\
\hline $60 \%$ & - & 28,8 & \\
\hline Mais de $60^{\circ}$ & & 29,9 & \\
\hline
\end{tabular}

Fonte: Central Labor Relates Commission in: OMI, Naoto. "Labor sets its sights on the 1.800-hour year". Economic Eye. Soring 1992, Tokio, Keizai Koho Center, p. 12.

\section{CONTEXTO ECONÔMICO}

As crescentes reduções salariais no Brasil, com a perda do poder aquisitivo, associadas a perspectivas de maiores remunerações nos países do primeiro mundo, levaram a um aumento da emigraçāo.

Há uma demanda por mão-de-obra no mercado de trabalho japonês, principalmente nas pequenas e médias empresas e também para a mão-de-obra não qualificada. ${ }^{8}$ Em virtude da Fonte: Somutyo adaptado de YANO, Itiro. Issen Kyuhaku Nanajuninenkan Nihon dificuldade para o preen- Kokuzei Zue. Anuário Kokuzei do Japão: 1990. Tóquio. Kokuzei-Sha. 1991. chimento destes postos por trabalhadores locais, trabalhadores não qualificados estavam sendo contratados de países em desenvolvimento do Sudeste Asiático. ${ }^{9}$ Desde a segunda metade da década de 1980, trabalhadores nikkeis latinoamericanos também estão se dirigindo ao Japão.
Johnston afirmava, na análise das migraçōes: "...Países que possuem uma força de trabalho que cresce devagar mas cuja oferta de empregos nos setores de serviços se amplia constantemente, como Japão, Alemanha e Estados Unidos, servirão de imä para imigrantes, mesmo que suas politicas busquem desestimular tal fenômeno..." 10

E este é o caso do Japão, que tem como política não incentivar a imigração, mesmo com problemas com a falta de mão-deobra.

\section{Tabela 15}

Evolução da força de trabalho no Japão

\begin{tabular}{|c|c|}
\hline Ano & 197019852000 \\
\hline $\begin{array}{l}\text { № de trab } \\
\text { (milhões) }\end{array}$ & $51,5 \quad 59,6 \quad 64,3$ \\
\hline
\end{tabular}

Fonte: JOHNSTON, William B. "O trabalho também nāo tem pátria". Negócios em Exame, 10 de julho de 1991, p. A-2.

Pode-se ver na tabela 15 que o Japão continuará a ter problemas com a falta de mão-de-obra, ocasionada pela baixa taxa de natalidade e o envelhecimento da população.

Os reflexos desta escassez aparecem em um maior período de trabalho diário no Japão, se comparada com a de outros países industrializados.
Outro fator determinante para o agravamento da escassez de mão-de-obra na indústria, setor da economia para onde se dirige uma grande parcela dos dekasseguis, é a própria tendência de a força de trabaIho se dirigir para o setor terciário da economia (Ver tabela 16). 


\section{Tabela 17}

\section{Produto nacional bruto real - Mercado} de mão-de-obra (sazonalmente ajustado)

\begin{tabular}{|c|c|c|}
\hline Ano & $\begin{array}{l}\text { \% aumiento em relacio } \\
\text { ao periodo anterior } \\
\text { ajustado sazonalmente }\end{array}$ & $\begin{array}{l}\text { Proporça de oferta } \\
\text { de trabalho relativa a } \\
\text { demanda de trabaho }\end{array}$ \\
\hline 1986 & 2,6 & 0,62 \\
\hline 1987 & 4,3 & 0,70 \\
\hline 1988 & 6,2 & 1,01 \\
\hline 1989 & 4,8 & 1,25 \\
\hline 1990 & 5,2 & 1,40 \\
\hline
\end{tabular}

Fonte: Economic Eye, Spring 1992.

O crescimento econômico do Japão agravou a escassez de mão-de-obra, conforme os dados da tabela 17. Por exemplo, em 1990 ocorreram 1,4 ofertas de empregos para cada trabalhador à procura de emprego. Esta relação entre a oferta e a demanda de trabalho é geral e não constitui trabalhos específicos. Assim, para o caso de trabalhos desqualificados e em pequenas e médias empresas, a hipótese é que esta taxa seja maior ainda. ${ }^{11}$

\section{A VISÃO EMPRESARIAL}

O investimento de capital japonês no mundo intensificou-se na década de 1950. Empresas transnacionais japonesas investiram nesta década no Brasil, principalmente nas áreas têxtil, de maquinários, siderúrgicas e na construção naval; as áreas alimentícias, químicas e eletro-eletrônicas tiveram aportes iniciais de capital japonês na década de 1960; enquanto os investimentos em projetos de grande porte nas áreas de celulose, siderurgia e alumínio foram privilegiados na década de 1970 . Além desses investimentos no setor industrial, foram realizadas inversões no setor terciário, com a instalação de bancos, seguradoras, hotéis, entre outros empreendimentos. ${ }^{12}$

Entre abril de 1951 e abril de 1990, US\$ 5,946 bilhões foram investidos no Brasil pelo capital japonês, o que representa $2,34 \%$ do total de investimento direto japonês no mundo durante esse período, e é o equivalente a $50,1 \%$ do total de investimentos japoneses na América Latina, desconsiderando os capitais invertidos nos paraísos fiscais (Panamá, Bahamas e Illhas Caymans) ${ }^{13}$
O Brasil como país receptor do capital direto japonês encontra-se em $9^{\circ}$ lugar pelo montante agregado desse período. De 1951 até 1985, o Brasil sempre se encontrava entre os dez primeiros países para os quais mais se dirigia o capital japonês. De 1977 a 1979 ocupava o $3^{\circ}$ lugar. Entretanto, a partir do ano seguinte, houve uma queda nessa classificação, o que significa a diminuição dos aportes de capital ao Brasil vis a vis a outros países da Ásia ou industrializados. $^{14}$

Apesar de o desprivilegiamento do Brasil como país receptor de investimento direto japonês na década de 1980 , as inversões de capitais japoneses para o Brasil no passado foram maciças, pois era considerado um importante país para a instalação de subsidiárias, filiais, joint-ventures, $\mathrm{e}$ de representação de empresas japonesas.

\section{De 1951 até 1985, o Brasil sempre se encontrava entre os dez primeiros países para os quais mais se dirigia o capital japonês.}

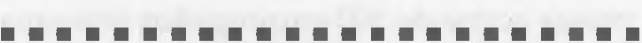

Diversas razōes fizeram com que nestas empresas japonesas instaladas no Brasil houvesse o recrutamento e seleção de japoneses e seus descendentes. Algumas das razões foram a dificuldade de comunicação dos administradores japoneses e de adaptaçāo cultural das empresas e desses administradores.

As possíveis implicações administrativas e econômicas do fenômeno dekassegui nas empresas foram o objeto da pesquisa realizada junto àquelas associadas à Câmara de Comércio e Indústria Japonesa no Brasil $^{15}$. Levantaram-se a percepção e as atitudes dessas empresas em relação a este fenômeno. ${ }^{16}$

\section{Perfil das empresas}

Enquanto tamanho das empresas, temse a distribuição que pode ser visualizada e verificada na tabela 18 .

Das empresas constantes na amostra, $51 \%$ são micro e pequenas, com menos de 100 empregados. São grandes empresas (mais de 3.000 empregados) 4\% da amostra. Constatou-se que as empresas da
11. "O rápido crescimento econômico tez aumentar... a demanda de máo-de-obra nåo especializada no Japăo que, na década de 1960, o excedente de mäo-de-obra transtor. mara-se em escassez...como resultado, os salários da mâa-de-obra näo especializada, empregada scbretudo na acricultura e em empresas de pequeno e médio porte, eleva. ram-se rapidamente. A lormaçāo de capital tendia a ocorres basicamente em grandes empresas, as pequerase ertédias introduziram lentamente os equipamentos modemos"...

"Pode-se [dizer]'...sobre o futuro crescimento populacional no Japão [que o... crescimento soterá uma dramática redução e se não chegar a zero, eslará próximo desta marca no ano 2015. Conludo, a laxa de aumentio da populaçâa de fáxa etäria superior a 65 aumentará..."

..."A queda da laxa de crescimento populacional e o envelhecimento da populaçáo causerăo uma reduçäo no aumento de lomecimento de mäo-de-obra. Isio agudizará o problema da escassez de máo-de-obra, sustando o crescimento econômico, pois salários elevados acarretam uma queda no retorno do capital e no investimento privado", MINAMI, Ryoshin, O crescimento economico do vapāo: perspectiva a longo prazo. Rio de Janeirc, Centro de Economia Mundial da Es. coladePós-GraduaçáoemEconomiada FGV, 1992, p. 9,18-19, mime0.

12. HOLLERMAN, Leon (1988). Japan's Economic Sirategy in Brazil: Challenge tor the Unized Stales. Massachusetts. Lexington. 1988.

13.SAAVEDRA-RIVANO, Neantro. "Japanese Direct Investment in Birazi|". Ensaios Econo. micos, n 168 . Rio de Janeiro. Escola de PósGraduaçao em Economia da FGV. 1990.

14. SAAVEDRA-RIVANO Neantro. Op. cit.

15. As empresas associadas na Câmara de Comerecio e Indústria Japonesa no Brasill, em 1991, responderam a uma variada gama de questoes, entrite as de múltipla escolhae aber. tas. Optou-se como método de coleta de da. dos oenvio pelo ccrreio de questionárics para as 327 empresas. Responderam ao questionário 48 empresas, $14,5 \%$ do universo da pesquisa, que se constituiu na amostra.

16. KATO, Hetor T, MIYAZAKI, Sívio YM. $\mathrm{SUGO}_{4}$ Alberto I. "Exodo de Trabalhadores Nikkeise as Empresas no Brasil|, Japão informativo Económico. Rio de Janeiro. Centro de Estudos Japoneses da Escola de PósGraduaçāo em Economia da FGV .III (11):2-4, Abríl ce 1992. 
17. SUKAMOTO,T. \& SCHWARTZ, G. Changesinthe industrial Structure and the Role of Small and Medium Industries in Deveioping Countries: the Case of Brazil. Tokyo. Institute of Developing Economies. 1990.
Tabela 18

\section{Porte de empresas por número de funcionários}

\begin{tabular}{|lcc|}
\hline $\begin{array}{l}\text { Número de } \\
\text { empregados }\end{array}$ & Empresas & Percentual \\
\hline Até 50 & 14 & $29,2 \%$ \\
\hline De 51 a 100 & 11 & $22,9 \%$ \\
\hline De 101 a 200 & 4 & $8,3 \%$ \\
De 201 a 500 & 7 & $14,6 \%$ \\
\hline De 501 a 1000 & 6 & $12,5 \%$ \\
De 1001 a 3000 & 4 & 8,3 \\
Mais de 3000 & 2 & $4,2 \%$ \\
Total & 48 & $100,0 \%$ \\
\hline
\end{tabular}

amostra, quanto ao número de funcionários, são distribuídas ao longo de todo o espectro das classes. Entretanto, verificouse que a amostra é mais concentrada nas classes abaixo de 100 empregados. Uma outra pesquisa sobre pequenas e médias empresas $^{17}$ constatou uma proporção desta classe bem menor na sua amostra $(25,5 \%)$. No outro extremo, a faixa de empresas acima de 500 empregados tem uma proporção menor $(25 \%)$ do que a verificada na amostra daquela outra pesquisa $(44,2 \%)$.

\begin{tabular}{|c|c|c|}
\hline \multicolumn{3}{|c|}{$\begin{array}{c}\text { Proporção de nikkeis no quadro } \\
\text { das empresas }\end{array}$} \\
\hline $\begin{array}{l}\text { Proporcáa } \\
\text { de nikkeis } \\
\text { na empresa }\end{array}$ & Número & Percentual \\
\hline De 90 a $100 \%$ & 4 & $8,3 \%$ \\
\hline De 75 a, $90 \%$ & 1 & $2,1 \%$ \\
\hline De 50 a $75 \%$ & 7 & $14,6 \%$ \\
\hline De 25 a $50 \%$ & 7 & $14,6 \%$ \\
\hline De 10 a $25 \%$ & 12 & $25,0 \%$ \\
\hline Ate $10 \%$ & 17 & $35,4 \%$ \\
\hline Total & 48 & $100,0 \%$ \\
\hline
\end{tabular}

Quanto à proporção de empregados nikkeis, 60,4\% das empresas empregam no máximo $25 \%$. Por outro lado, há empresas $(8,3 \%)$ constituídas por mais de $90 \%$ de nikkeis. Estes dados mostram a significância da amostra para se verificar a mobilidade de empregados nikkeis em empresas face ao fenômeno dekassegui.
O grau de importância do nikkei nas operações e atividades nessas empresas apresentou os seguintes percentuais: $39,6 \%$ das empresas assinalaram que eles são importantes mas não insubstituíveis. $\mathrm{E}$ $25,0 \%$ opinaram serem necessários para as atividades. O nikkei somente é essencial para $10,4 \%$ das empresas. As justificativas mais frequientes para a avaliação da importância do nikkei na empresa foram o conhecimento da língua japonesa e a capacidade técnica para qualquer tipo de tarefa.

Quanto à remuneração dos nikkeis que mais se demitiram e foram ao Japão trabalhar, os maiores percentuais de faixas salariais foram a de um a cinco salários mínimos $(32,82 \%)$ e a de seis a dez salários mínimos (39,33\%), o que comprova serem eles os ocupantes de tarefas semiqualificadas, reforçando a hipótese de que causas econômicas, no caso a remuneração relativamente baixa, contribuem para a dinâmica do fenômeno dekassegui.

\section{Indicadores da saída}

Aproximadamente um terço das empresas $(35,4 \%)$ tem uma saída de até $10 \%$ de nikkeis para o Japão. Os dois terços restantes apresentam percentuais altos de saída, sendo um terço $(31,3 \%)$ de 11 a $50 \%$ e o terço final $(31,3 \%)$, de mais de $50 \%$ de saídas para o Japão.

\section{Tabela 20}

Sairam da empresa e foram trabalhar no Japão

\begin{tabular}{|lcc|}
\hline & Numero & Percentagem \\
\hline Até $10 \%$ & 17 & $35,4 \%$ \\
\hline De 11 a $25 \%$ & 7 & $14,6 \%$ \\
\hline De 26 a $50 \%$ & 8 & $16,7 \%$ \\
Mais de $50 \%$ & 15 & $31,3 \%$ \\
\hline Não respondeu & 1 & $2,1 \%$ \\
Total & 48 & $100 ; 0 \%$ \\
\hline
\end{tabular}

Esses dados mostram uma tendência de aumento das saídas para o Japão, principalmente em virtude do fenômeno dekassegui. A partir de 1989, o aumento se destaca na coluna da classificação "De 16 a 30\%" conforme pode-se observar na apresentação consolidada das saídas dos nikkeis, de acordo com tabela 21. 
Tabela 21

Percentagem de nikkeis que sairam da empresa e turn-over

\begin{tabular}{|cccccc|}
\hline Ano & Alé $5 \%$ & $15 \%$ & $30 \%$ & $50 \%$ & $50 \%$ \\
\hline 1985 & 66,7 & 12,5 & 2,1 & 2,1 & 2,1 \\
\hline 1986 & 64,6 & 12,5 & 4,2 & 0,0 & 4,2 \\
\hline 1987 & 60,4 & 12,5 & 6,3 & 0,0 & 4,2 \\
\hline 1988 & 60,4 & 14,6 & 6,3 & 2,1 & 2,1 \\
1989 & 50,0 & 16,7 & 16,7 & 2,1 & 6,3 \\
\hline 1990 & 58,3 & 14,6 & 14,6 & 6,3 & 4,2 \\
\hline Turn-over & 45,8 & 27,1 & 22,9 & - & - \\
\hline
\end{tabular}

condiz com uma suposição de que é razoavelmente alta a remuneração salarial deles e sua posição na sociedade;

3) para os semiqualificados e os especializados/técnicos o fator social não foi decisivo para continuar no Brasil, preferindo a opção de trabalhar no Japão por uma remuneração maior, ainda que em ocupações não qualificadas ou diferentes da formação ou qualificação deles.

Dentre os principais motivos apontados para a ida desses ex-funcionários ao Japão, estão as razões econômicas, sejam a instabilidade e insegurança que a atual situação econômica traz, seja o desequilíbrio da situação econômica familiar dadas essas condições econômicas. A "ambição de ganhar muito e rapidamente" foi uma das alternativas que mais as empresas assinalaram.

A sugestăo para ir ao Japão por parte de amigos, parentes e conhecidos indica que a rcdc dc informações na comunidade japonesa tem influência quanto ao fenômeno dekassegui.

\section{Efeitos e atitudes das} empresas quanto ao fenômeno

As empresas informaram que a melhoria da qualidade dos trabalhadores e o acesso e transferência de tecnologia são os possíveis beneficios que os dekasseguis poderão trazer ao país com o seu retorno. Entretanto, em grande parte das empresas (75\%), nenhum ex-empregado, dos que retornaram ao Brasil, voltaram às empresas de origem. Assim, uma hipótese é que as empresas não têm um plano de recolocação dos ex-dekasseguis, não aproveitando as novas habilidades técnicas e conhecimentos adquiridos no Japão.

O movimento de transferência de mãode-obra é visto como um problema econômico $(64,6 \%)$, social $(31,3 \%)$ e temporário $(29,2 \%)$ pelos adminstradores. Na opinião das empresas, esse movimento continuará enquanto permanecerem as di- 
ficuldades econômicas no Brasil e o Japão mantiver o seu crescimento econômico.

\section{Tabela 22}

O que a empresa está fazendo?

\begin{tabular}{lcc|} 
Aconselhamento & 16 & $33,3 \%$ \\
\hline Possibilidade de promoção & 4 & $8,3 \%$ \\
Possibilidade de aumento & & \\
salário e benefícios & 4 & $8,3 \%$ \\
\hline Dificultar a saída & 0 & $0,0 \%$ \\
Năo faz nada & 25 & $52,1 \%$ \\
\hline Outros & 1 & $2,1 \%$ \\
Em branco & 3 & $6,3 \%$ \\
\hline
\end{tabular}

A principal atitude das empresas é "não faz nada" seguido de "aconselhamento". Essas atitudes, além de uma opção da empresa, podem resultar da dificuldade com a falta de meios e instrumentos efetivos para manter os funcionários. Esse fato pode ser devido à situação econômica desfavorável do Brasil e, portanto, à impossibilidade de as empresas poderem melhorar as condições de remuneração (através, por exemplo, de promoções, aumento de salários e ampliação de benefícios) dos empregados. A importância relativa destes na estrutura de trabalho é uma outra razão, uma vez que os dekasseguis são em grande parte semiqualificados e especializados/técnicos (Ver tabela 22).

Nas empresas, os principais efeitos das saídas dos empregados nikkeis foram a contratação e a ampliação do número de funcionários não nikkeis e dificuldades de

\section{Tabela 24}

\begin{tabular}{|c|c|c|c|c|}
\hline & \multicolumn{2}{|c|}{ Aconselhamento } & \multicolumn{2}{|c|}{ Não faz nada } \\
\hline & $\mathrm{N}^{2}$ & $\%$ & № & $\%$ \\
\hline Essencial & 2 & 12,5 & 3 & 10,3 \\
\hline $\begin{array}{l}\text { Importante mas } \\
\text { nāo-insubstituivel }\end{array}$ & & 43.8 & 13 & 44,8 \\
\hline $\begin{array}{l}\text { Necessário para o tipo } \\
\text { de administração }\end{array}$ & 0 & 0,0 & 4 & 13,8 \\
\hline $\begin{array}{l}\text { Necessário para algumas } \\
\text { atividades }\end{array}$ & 5 & 31,3 & 5 & 172 \\
\hline Totalmente substituiveis & 1 & 6,3 & 4 & 13,8 \\
\hline Outros & 1 & 6,3 & 0 & 0,0 \\
\hline Total & 16 & 100,0 & 29 & 100,0 \\
\hline
\end{tabular}

Tabela 23

Efeitos das saídas dos funcionários

\begin{tabular}{|c|c|c|}
\hline Acúmulo de taretas & 12 & $25,0 \%$ \\
\hline Diminuição da produçāo & 1 & $2,1 \%$ \\
\hline $\begin{array}{l}\text { Diminujẹaa da qualidade de } \\
\text { serviços e produtividade }\end{array}$ & 5. & $\$ 0,4 \%$ \\
\hline $\begin{array}{l}\text { Maior necessidade de } \\
\text { treinamento }\end{array}$ & 9 & $18,8 \%$ \\
\hline Dificuldades de treinamento & 19 & $39,6 \%$ \\
\hline $\begin{array}{l}\text { Aumento da folha } \\
\text { de pagamento }\end{array}$ & 5 & 10,4 \\
\hline $\begin{array}{l}\text { Contrataçáo de funcionários } \\
\text { não-descendentes }\end{array}$ & 22 & $45,8 \%$ \\
\hline Dificuldades de comunicação & 07 & $14,6 \%$ \\
\hline Outros & 6 & $12,5 \%$ \\
\hline Em branco & 3 & $6,3 \%$ \\
\hline
\end{tabular}

treinamento. $\mathrm{O}$ aumento das dificuldades de treinamento pode ser associado tanto à maior contratação de não descendentes, tendo como consequiência problemas de comunicação e diferenças culturais, quanto ao próprio volume de contrataçōes. Entretanto, dificuldades de comunicação foram relatadas por apenas $14,6 \%$ das empresas. Por outro lado, o acúmulo de tarefas pode ser função de os nikkeis remanescentes nas empresas terem assumido mais tarefas por causa do domínio da língua e experiência nas empresas. Vale lembrar que os empresários justificaram que o nikkei é importante para a empresa, principalmente pelo conhecimento da língua japonesa.

Verifica-se que não há grande impacto da variável percepção quanto ao nikkei ("importância do nikkei nas suas operações") sobre a atitude das empresas. Ressalte-se que, mesmo entre as duas atitudes das empresas ("não faz nada" e "aconselhamento", que representaram $85,4 \%$ das respostas), não há diferença substancial.

\section{CONCLUSÃO}

O fluxo de migração dos trabalhadores para o Japão tem alterado significativamente a vida econômica, social e cultural da comunidade japonesa no Brasil. Embora determinada parcialmente pela conjuntura econômica no Brasil, a dinâmica do movimento não acompanhou diretamente os movimentos na economia nacional. 
Inicialmente, começando como uma atividade não aceita dentro da comunidade, as dificuldades econômicas persistentes no Brasil e o relato de sucesso na acumulação de uma poupança através de trabalhos não qualificados no Japão levaram um número crescente de pessoas a integrarem este fluxo migratório. O aumento do volume de migrantes fez surgir a figura do intermediário e das firmas intermediárias, que, por sua vez, deram um outro caráter ao movimento com seus métodos de recrutamento.

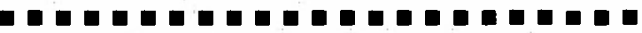 \\ Com o retorno ao Brasil dos dekasseguis, quais seriam as condições para sua reintegração no mercado de trabalho?}

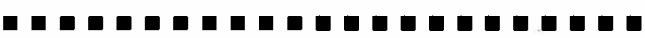

A partir de um certo momento, a apreciação da comunidade nipo-brasileira quanto ao movimento se modificou, passando a aprová-lo. Associado ao surgimento dos intermediários, isto fez com que pessoas sem nenhuma noção do que iriam encontrar fossem trabalhar no Japão. A análise do perfil dos dekasseguis revela que há uma boa diferenciação entre os perfis daqueles que pretendem retornar ao Japão e aqueles que não pretendem repetir a experiência. O domínio da língua parece ser um fator determinante para esta diferenciação, mas pode ser também apenas um indicador dos verdadeiros determinantes que não foram levantados.

A investigação quanto ao impacto do fenômeno nas empresas pesquisadas permitiu verificar que o fluxo migratório ao Japão foi sentido pelas empresas. As principais consequiências foram dificuldades de recrutamento, maior necessidade de treinamento e acúmulo de tarefas. Salienta-se a falta de qualquer programa para a manutenção desses trabalhadores nas empresas, com a maioria das empresas não fazendo nada ou apenas aconselhando e poucas empresas oferecendo salários maiores.

Para finalizar, será apresentado um possível cenário das perspectivas do dekassegui, dentro da atual conjuntura econômica do Brasil e Japão, relevando a condição do dekassegui enquanto força de tra- balho reabsorvida pelas empresas no Brasil.

Ao se inscrever num processo de seleção numa empresa, os descendentes de japoneses estão tendo dificuldade em continuar no processo de seleção, pois há por parte das empresas o receio em selecionar, treinar e ver esse investimento ser perdido. Isto aconteceria, eventualmente, quando, surgindo melhores propostas de emprego no Japão, eles se demitissem após o treinamento recebido na empresa para viajar ao Japão $0^{18}$. Assim, há algumas conseqüências quanto ao emprego mesmo para aqueles que não foram trabalhar no Japão, como está sendo percebido na imprensa no Brasil.

Com a recente queda do crescimento econômico do Japão, a oferta de trabalho e principalmente a necessidade de horasextras têm caído, fazendo com que alguns dekasseguis tenham que, voluntariamente ou não, retornar ao Brasil, mesmo sem a esperada independência econômica. ${ }^{19}$

Com o retorno ao Brasil dos dekasseguis, quais seriam as condições para sua reintegração no mercado de trabalho?

O conhecimento de língua japonesa, uma qualificação imediata dos nikkeis, não parece constituir uma vantagem ou um diferencial para os ex-dekasseguis. Os que melhor dominavam o japonês são exatamente aqueles com maior chance de sucesso e permanência no Japão. Há aqueles que foram bem-sucedidos em seus planos de poupar para abertura de pequenos negócios e aqueles que pretendem fixar residência no Japão. É provável que retornem primeiro, em ordem, aqueles com menor conhecimento de língua japonesa, menor adaptação cultural e social no Japão, além de outras razões financeiras.

Para um ex-dekassegui, a saída do mercado de trabalho no Brasil causa-lhe um ônus em termos de perda de qualificação profissional, destreino pelo período ausente de uma ocupação mais qualificada e desatualização. Além, disto, eles estão fora das redes de emprego, além das esperadas dificuldades de readaptação pessoal no Brasil.

Sem mecanismos sociais e econômicos de recolocação profissional, o cenário para o dekassegui indica dificuldades maiores do que apenas o problema individual de readaptação.
18. O ESTADO de São Paulo. Caderno 2.p.3,31 de março de 1991.

19. KANAMORI, Hisao. "Year of Adjustment". Journal of Japanese Trade \& Industry. $n^{0} 1 / 1992$. 